\title{
AVAILABILITY AND COMPARISON OF DATA FROM SENTINEL- 1 SATELLITES IN AREAS OF INTEREST IN THE CZECH REPUBLIC AND SUDAN
}

\author{
Dominik Brétt ${ }^{1,2}$
}

\author{
1. Czech Technical University in Prague, Faculty of Civil Engineering, Department \\ of Geomatics, Prague, Thákurova 2077/7, 166 29, Czech Republic \\ 2. Faculty of Environment, J. E. Purkyně University in Ústí nad Labem, Pasteurova \\ 3632/15, 40096 Ústí nad Labem, Czech Republic \\ ;dominik.brett@fsv.cvut.cz
}

\begin{abstract}
The article is focused on the methodology of processing interferometric images and associated challenges with the processing. The article also contains useful links with explanations that can be used for processing data from the Sentinel-1 satellite. To emphasize the data limits of Sentinel-1, several areas of interest were chosen for comparison - in the home environment of the Czech Republic, the Bílina quarry area, and the Žatec area were selected. For subsequent comparison, arid areas with a rich history located in Sudan were selected. The colleagues of the author from the Faculty of The Environment of Jan Evangelista Purkyně University participate in expeditions there. Each of these locations is limited by different parameters - the areas in the Czech Republic are mainly limited by location because of occurring vegetation. Sudan's regions, on the other hand, are arid but are limited by insufficient coverage by capturing the Sentinel-1 satellite. To create digital height models from Sentinel-1 satellite data, it is necessary to search for data with sufficient coherence of images, and parameters of the amount of vegetation with a period between individual images play an important role. The areas were compared with each other and with the commonly available SRTM elevation model, both from a visual point of view - where digital height models and shaded surface models were created, as well as statistically using RMSE.
\end{abstract}

\section{KEYWORDS}

InSAR, Remote Sensing, Sentinel-1, GIS, RMSE

\section{INTRODUCTION}

Almost from the earliest days of mapmaking, people have tried to express elevation in these maps. They used, for example, drawn hills, hatching, and last but not least, contour lines [1]. Today's age of digital technology makes it possible to model the landscape in the form of digital elevation models. Various contact and non-contact data collection technologies are now commonly used to derive digital elevation models [2]. Non-contact data collection methods, such as photogrammetry and airborne laser scanning, allow the creation of very detailed digital terrain and surface models, but it is always necessary to send a vehicle equipped with the chosen type of sensor to the area of interest [3]. This is a limitation for the creation of digital terrain models in areas with limited accessibility. Here, there is an opportunity for the use of radar interferometry methods where a satellite is used as a carrier [4].

The Sentinel-1 mission is aimed at monitoring sea ice, ocean waters, the coastline, and polar regions, as well as monitoring the land itself, building in particular on successful Envisat and ERS-1 satellite missions. For Europe, their possible use in crisis management is especially important, mainly due to the availability of up-to-date data almost in real-time. Specific data utilization is 
foreseen for flood or terrain deformations, which can be detected with millimeter accuracy with appropriate images using radar interferometry [1].

A major advantage of radar data, as opposed to optical data, is that it can be acquired when the sky is covered with clouds. This can be used, for example, to monitor current flood events caused by rainfall. Another area of application for Sentinel-1 data is the monitoring of the territory - e.g., forest mapping, monitoring of crops, or monitoring of the extent of snow cover. Similar information can also help predict floods or monitor the impact of climate change [5].

The use of Sentinel-1 data brings several general advantages - firstly, the data are freely downloadable on the official ESA site, and secondly, the mission Sentinel-1 provides almost realtime data of the whole World. The mission satellite is using synthetic aperture radar [6].

The objectives of this paper are aimed at understanding the processing, and the subsequent analysis of radar data from the Sentinel-1 mission. The satellites of this mission operate based on InSAR - interferometric radar with synthetic aperture. Digital elevation models of areas of interest were derived from the processed data, which were subsequently compared visually and statistically.

\section{DATA AND METHODS}

The creation of a digital elevation model (DEM) was not the main objective of the Sentinel-1 mission in comparison with SRTM, where generating the most complete high-resolution digital topographic database of Earth was the primary objective. The main objective of Sentinel-1 is designed to provide enhanced revisit frequency, coverage, timeliness, and reliability for operational services and applications requiring long time series and the constellation will cover the entire world's landmasses on a bi-weekly basis, sea-ice zones, Europe's coastal zones and shipping routes on a daily basis and open ocean continuously by wave images. It is not possible to apply this procedure of creating the DEM to the whole World, even if the data of the area are available. The process of DEM derivation is based on the InSAR data hardware-intensive and it is necessary to take into account long-lasting processes, especially for less powerful devices.

\section{Area of interest}

To derive a DEM from Sentinel-1 data, it is important to select a suitable area. Sentinel-1 works in band $\mathrm{C}$, which in practice means that vegetation has a big influence on the quality of the model. Unfortunately, the beam cannot penetrate a layer of vegetation with its rays, and modeling, for example, within the rainforest environment is impossible from this data.

A total of four test areas were thus chosen - two areas in the Czech Republic and two areas in Sudan. Within the Czech Republic, areas with low vegetation were sought, thus the sites Bilina open-pit quarry and an area within the Zatec municipality were processed (see Chyba! Nenalezen zdroj odkazú.). These areas were selected because the vegetation cover is completely removed

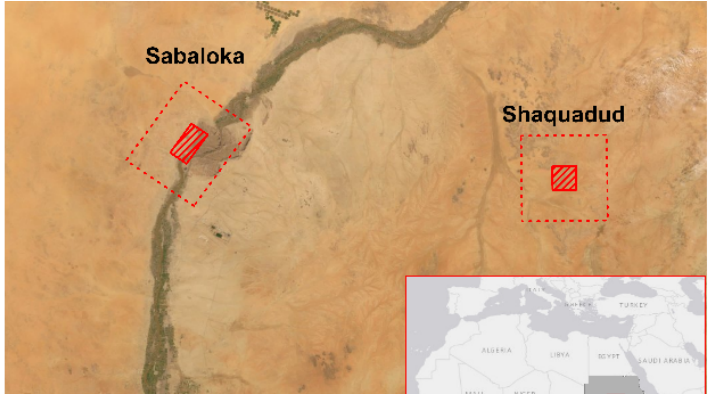

Fig. 2 - Localization of the study area within Sudan Author: Dominik Brétt, 2021

Ortophoto: Esri, DigitalGlobe, GeoEye, i-cubed, USDA FSA, USGS, AEX, Getmapping, Aerogrid, IGN, IGP, swisstopo

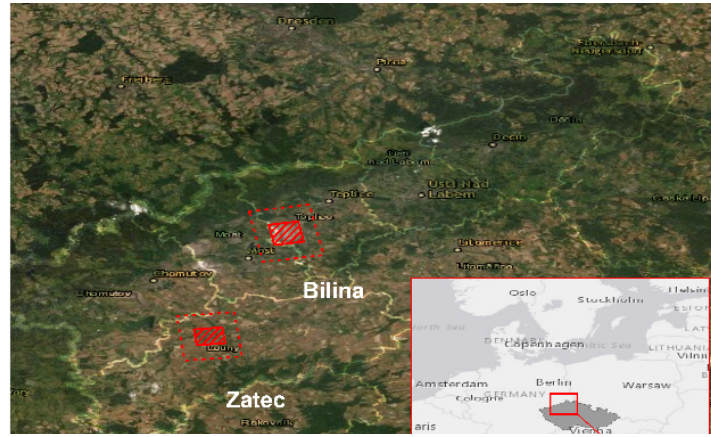

Fig. 1- Localization of the study area within Czechia Author: Dominik Brétt, 2021

Ortophoto: Esri, DigitalGlobe, GeoEye, i-cubed, USDA FSA, USGS, AEX, Getmapping, Aerogrid, IGN, IGP, swisstopo 
during opencast mining and the Zatecko region represents a typical Central European landscape with a low incidence of higher vegetation.

The sites in Sudan were chosen not only because of the desert nature of the landscape but also because, thanks to the cooperation on archaeological research with the Czech Institute of Egyptology, Faculty of Philosophy and Arts - Charles University in Prague and the Institute of Archaeology of the Czech Academy of Sciences, Prague [7, 8, 9], we have field-measured reference data to verify the quality of the resulting DEMs.

\section{Principles of Radar and InSAR}

The word "radar" originated from "radio detection and ranging". The device emits its electromagnetic radiation, these short and intense microwave signals are sent in a certain direction and part of the signal (so-called echo) is reflected from the objects. Radar systems can be located on the earth's surface, aircraft, and satellites and can create image recording. The Sentinel-1 satellite uses Synthetic Aperture Radar [10].

Synthetic Aperture Radar is a technically more complex device allowing acquisition of radar recordings. SAR carries a physically short antenna which transmits radiation that is reflected from the scanned surface. This procedure has a very narrow beam even at very large transverse distances from the carrier. To improve longitudinal spatial resolution, SAR uses Doppler's frequency shift. The signal recorded from the objects behind the carrier has a lower frequency. SAR then processes only the middle part of the beam - there is no shift in frequencies - and this significantly improves the longitudinal spatial resolution [11].

The device works with a combination of two or more radars and senses the topography of the terrain and its deformation from different angles. The resulting image has two parts of intensity and phase and both of these parts of the reflected beam [6]. The radar is mounted on the satellite with an antenna aimed at the Earth's surface in a plane perpendicular to the orbit - this is how it works in theory, but in practice, this is not entirely true to the rotation of the Earth around its axis. The antenna closes the angle with the ground normal (off-nadir angle) and in current systems, it is usually 34 in the range between $20^{\circ}$ and $50^{\circ}$. Due to the curvature of the Earth's surface, the incidence angle, i.e., the angle at the point of impact of the signal between the Earth's normal and the direction from which the signal is coming, is greater than the angle of view. For simplicity, it should be assumed that the Earth is flat and therefore the angle of impact is equal to the angle of reflection [6].

The basic principle of this method is the beam transmitted from the radar, with reflecting surfaces at different distances showing different response times between sending and capturing the beam. At the same time, the method uses changes in the phase of reflected radiation and the difference between two images of the same territory. Due to the almost pure sine nature of the transmitted signal, the T response is equal to the change in phase $\Phi$ between the transmitted and the captured beam. The phase change is therefore proportional to the two-way beam distance divided by the wavelength of the radar [6].

Radar data is processed by multiple sensing of a single location for the composition of the final image, and georeferenced using the earth's reference ellipsoid (e.g., WGS 84). The data is available in three spatial resolutions (Full Resolution, High Resolution, Medium Resolution) [12].

Synthetic aperture radar (SAR) is a radar system for data collecting using microwave length for measuring the distance from the satellite. Microwave length provides features such as penetrating the cloudy atmosphere, through this wavelength, it also recognizes the soil moisture. Synthetic aperture radar works without an external source of light - it means it can collect data in the nighttime - so it belongs to the category of active sensors [13].

Synthetic aperture radars record reflections where they add a specific value to each point and it is possible to obtain a reflection of one point from multiple angles thanks to the different orbits of orbiting satellites. These points will differ in their phase and create a difference - interference. The phase can be a carrier of the height of a given location, and interferometry is then a method of 
precise altitude measurement based on differences in the phase of two radar signals obtained from a different position [11].

The satellite is mounted with a radar with an antenna aimed at the Earth's surface in a plane perpendicular to orbit - this is how it works in theory, but in practice, this is not entirely true due to the rotation of the Earth around its own was. The antenna is closed by an angle with Earth's normal called an off-nadir angle and in current systems, it is usually in the range between $20^{\circ}$ and $50^{\circ}$. Due to the curvature of the Earth's surface, the angle of impact (incidence angle), that is, the angle at the point of impact of the signal between the Earth's normal and the direction from which the signal is coming, is greater than the angle of view. For simplicity, it should be assumed that the Earth is flat and therefore the angle of impact is equal to the angle of reflection [6].

Freely according to [14] and [11], by processing images, it is possible to create an interferogram and from it is possible to determine the relative height differences of the individual elements of the image, which can be further converted to the altitude of the terrain to build a digital model of the terrain [1].

\section{The basic geometry of radar images}

The configuration of satellites has an important role in InSAR processing. The base configuration can lead to different results, and thus the user should understand the main ideas and concepts of SAR geometry. The distance between two satellites and the axis, which is perpendicular to the orbit, is called the perpendicular baseline [6]. The perpendicular baseline has a positive effect on altitude accuracy. The larger this parameter is, the higher the accuracy. At the same time, however, if the perpendicular base is too long, coherence decreases. A critical parameter is a perpendicular base. From this limit, the signal becomes decorrelated, and interferometric stripes cannot be generated [15]. Another critical parameter is the temporal baseline - time between two satellite images. If the temporal base is high, the slightest growth of vegetation - leaves on trees or growth of the lower floor - is reflected in the picture. All this leads to an increase in decorrelation and thus to a decrease in the coherence of the images [16].

\section{Sentinel-1 data specifications}

Single Look Complex (SLC) are data georeferenced based on information about the orbit and altitude at which the imaging satellite observes. Compared to $\mathrm{GRD}^{1}$, it has a phase component that is suitable for interferometric processing [17]. The data is in a zero-Doppler orientation, where each row of pixels represents points along a line perpendicular to a sub-satellite path. SLC in Stripmap mode contains one frame for each shot for both polarizations. Interferometric Wide Swath mode, which has three frame bands, contains three images in simple polarization and six frames in dualpolarization. Extra Wide Swath mode consists of five 43 frame bars, five frames for simple polarization, and ten frames for dual-polarization [12].

Sentinel-1 data products are distributed in Standard Archive Format for Europe (SAFE), which was designed to archive and transmit ESA earth observation data while recommended for harmonizing data from all Copernicus satellites. SENTINEL-SAFE contains a folder with image data in binary data format and METADATA in XML format [5].

\footnotetext{
${ }^{1}$ Ground Range Detected - another data product of Sentinel-1 mission
} 
The name of the data package itself contains a lot of information about the product, which can be demonstrated by the example of a single paired image from the Bílina quarry area:

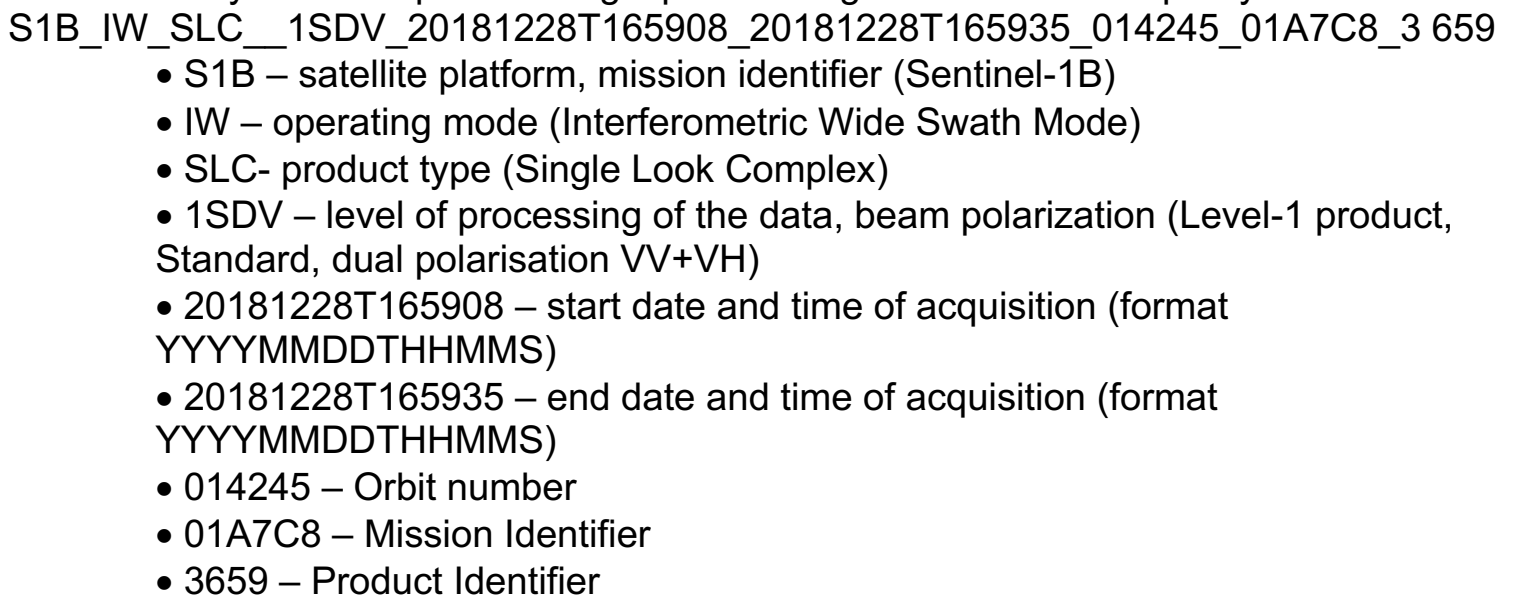

\section{Software and data sources used for Sentinel-1 data processing}

The processing of interferometric images is quite hardware-intensive and therefore it is recommended to process data on a powerful machine. The SNAP software was chosen for the processing of interferometric data. It is freely available software that offers tools for processing all Sentinel mission data even the Sentinel-1. A strong and active user community is also an advantage.

Before processing the data itself, it is important to install the snaphu unwrapping plugin. This plugin provides unwrapping the phase of the interferometric data, which is not supported in the software by default. The unwrapping plugin is located in the Tools Tab, in the Plugins section. In this section, the Available Plugins tab must be selected. The Plugin has to be active, this is done in the Tools tab in the Manage External Tools. After these steps, SNAP was ready to process interferometric data, which was subsequently opened using the Open Product button in the original ZIP folder.

Visualization and presentation of the results were carried out in the environment of the ArcGIS Pro software.

To select suitable data, a website from the Alaska Satellite Facility -Vertex tool [18](used, which, after selecting the data type and placing the polygon of areas of interest, searched for all data dealing with the selected area. Tool [18].

To find the correct paired image, another tool from the same institution was used, the Baseline

A portal from the European Space Agency [19] was used to obtain data. However, only 3 images can be downloaded at a time and only images under 2 years of age are available and older images must be requested.

There is an alternative for obtaining data for the Czech Republic, namely Collaborative Ground Segment, [20] which was created in cooperation with the CESNET association, the Czech Ministry of Transport, and the European Space Agency.

Before the actual image processing, the SNAPHU Unwrapping plug-in had to be installed in the SNAP software, which enabled the unwrapping of the phase.

\section{Verification of the quality of the resulting data}

Several datasets were used for the verification of the quality of the resulting DEMs. The SRTM (Shuttle Radar Topography Mission) was used for both test sites. The SRTM data were acquired on 22.11.2000 during the mission STS-99. It has started by launching two Endeavour satellites equipped with C-Band radar. This mission was under the protection of NASA and NGA and was launched to acquire radar data for the basis of the digital elevation model of the (almost) whole world. Elevation data offers worldwide coverage at a resolution of 1 arc-second (which is 30 meters in the 
metric system) and provides open distribution of this high-resolution global data set [21]. Data for this article were obtained from the website EarthExplorer [22], which is managed by the United States Geological Survey.

The areas in the Czech Republic were further compared with LiDAR data. There is lidar data for the whole area of the Czech Republic - DMR 5G. It is the newest lidar observation of the Czech Office for Surveying, Mapping, and Cadastre and it contains coordinates $\mathrm{X}, \mathrm{Y}, \mathrm{H}$, where H represents the altitude in the Balt elevation reference system after alignment (Bpv) with a total mean error of $0,18 \mathrm{~m}$ in exposed terrain and $0,3 \mathrm{~m}$ in forested areas. [23] Lidar data were obtained from web service ArcGIS Online.

The Root Mean Square Error (RMSE) is an advanced method for the determination of the accuracy of DEM. This method measures the variance of the frequency distribution of deviations between the two DEMs. The higher value of RMSE represents wider deviations between two datasets. The lower value of RMSE, the more accurate is the resulting model. The unit of RMSE is given by the input data.

\section{RESULTS}

\section{Sentinel-1 data processing}

After obtaining packages, data had to be in the zip folder and cannot be renamed or data would not be recognized by SNAP software. All the information that can be read from the name, as the date of observation, can be read by SNAP.

Orb Stack product was made as a result of S1-TOPS Coregistration with ESD. The purpose of this process is to shrink the examined territory and combine the data of input ZIP packages.

After coregistration, interferogram preparation was followed. As input data were used as output the results of the coregistration. This step is not important only for the whole workflow of processing radar data, but also in this step, the quality of the final output can be predicted. Interferogram acquires values from zero to one - the closer the value is to 1 , the less noise the images contain and the image is, the more quality.

After those steps, there were a few defects in the output image of the interferogram and other phases. First, black lines which were showing individual paths of the satellites. Second, noise that could be filtered. Black lines showing paths of the satellites were removed by process TOPS Deburst. The overlay of the paths was chosen and it got rid of the black lines. With Goldstein Phase filtering, the noise was reduced. As the name of this function suggests, it influences only the phase, and coherence remains the same. After that, the Raster subset was created to quicken the next step of this workflow.

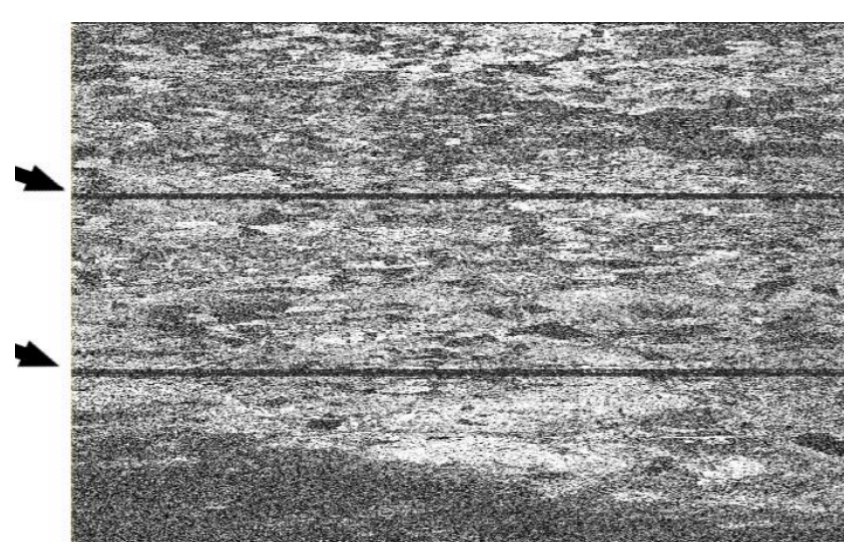

Fig. 3 - Black lines showing individual paths

At this moment, the plugin for the unwrapping phase was used and this step is the most challenging for the hardware.

For converting from radian units to absolute height was used function phase to elevation and the Range Doppler Terrain Correction was applied for geometric distortion and terrain correction. Output models were created with $15 \mathrm{~m}$ spatial resolution and were exported in the GeoTIFF format.

Software ArcGIS Pro was chosen for the next processing, where the digital elevation models were opened and then hillshaded models were created. In the hillshade tab there were inserted these parameters: azimuth 315, altitude 45 . The key parameter was z-factor and the value 0.000015 
was inserted. Every model was projected in WGS84 (which is based on degrees) and the height is given in meters.

The test data for the Czech Republic were acquired during the dormant season in the year 2018, due to the lowering decorrelation caused by vegetation cover during the summer. On the other hand, the selected areas were in the same data frame as the Ore Mountains are, and the results were not correlated as expected - even though the dormant season was present there is still vegetation cover such as grass or coniferous forests which are increasing the decorrelation.

The biggest limit in the Sudan areas was especially the temporary baseline, wherein at that time, only 12 days temporary baseline was found. Data was acquired also in the year 2018 .

For result comparison of processed Sentinel-1 data were used data from SRTM. 22.11.2000, this mission has started by launching two satellites Endeavour with radar with C-Band on board. This mission was under the protection of NASA and NGA and was launched to acquire radar data for the basis of the digital elevation model of the (almost) whole world [21]. The quality of the resulting models was verified also statically using RMSE. 


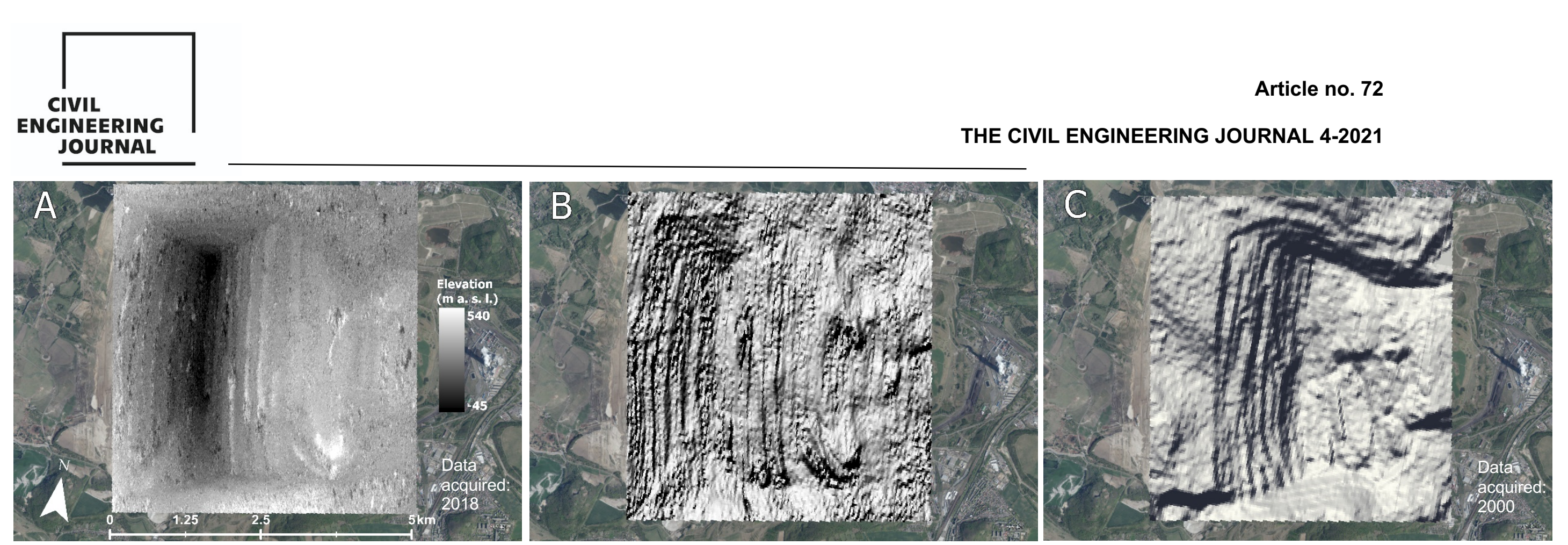

Fig. 4 - Resulting models of the Bílina quarry area, author: Dominik Brétt, 2021, orthophoto: ČúZK

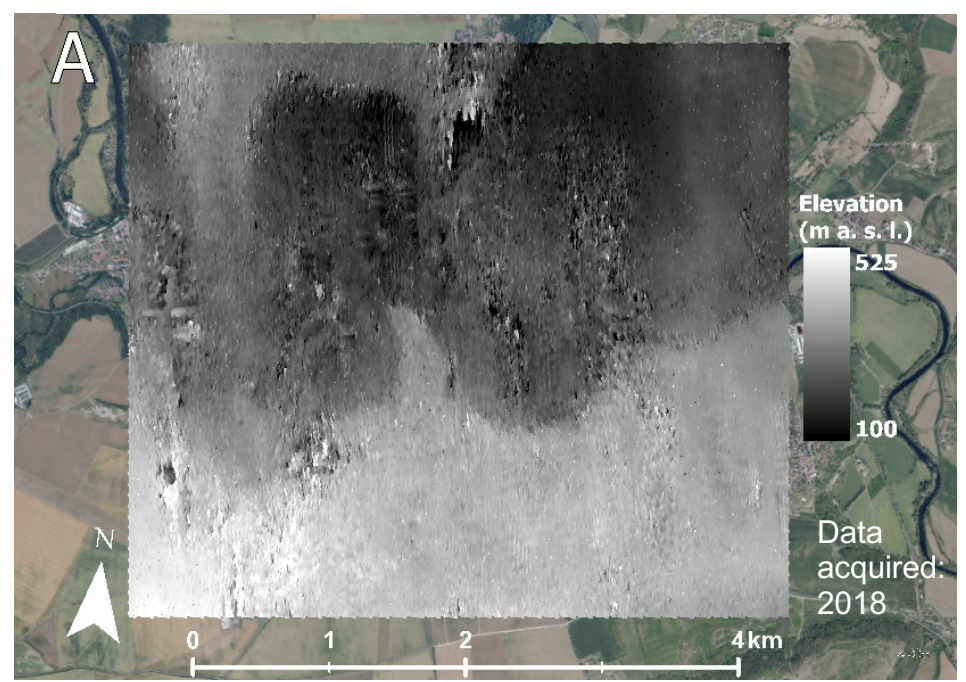

Fig. 5 - Resulting models of the Zatec area, author: Dominik Brétt, orthophoto: ČúZK

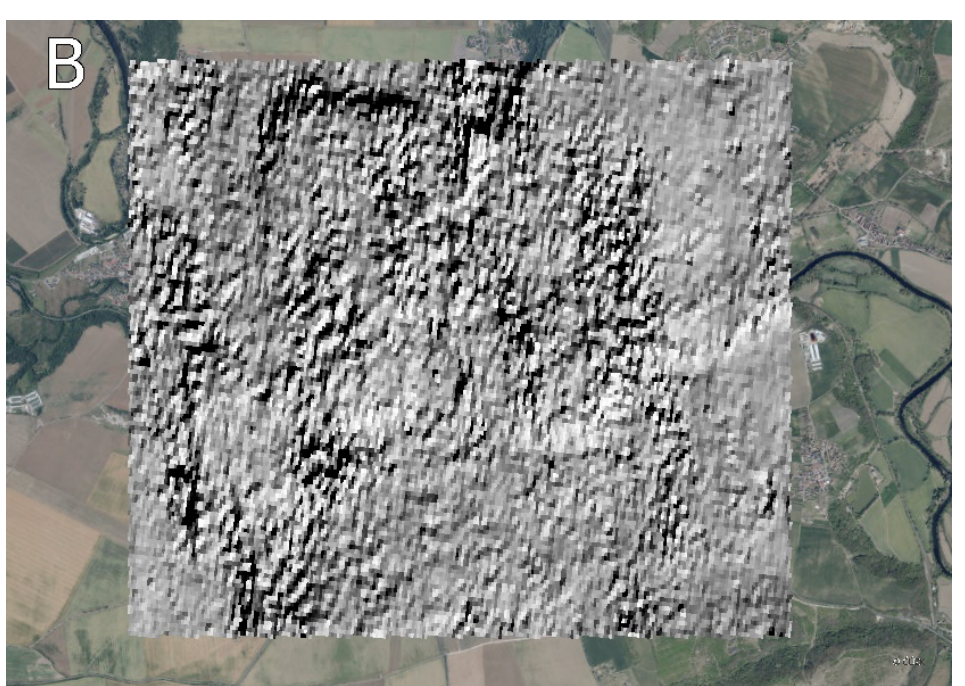

(

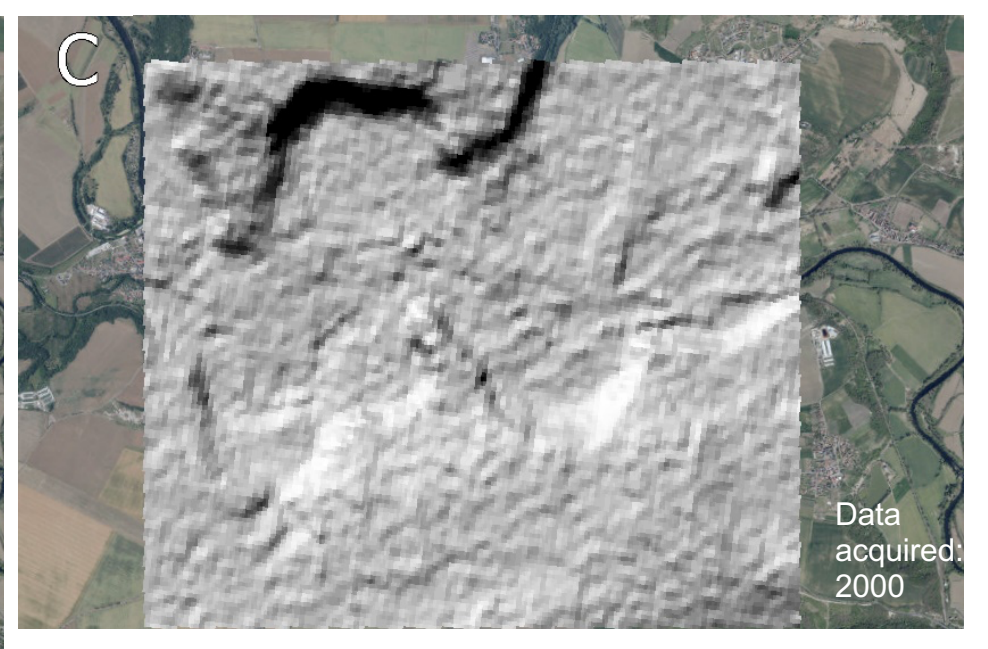

A - DEM processed from Sentinel-1 data B - Hillshaded model processed from Sentinel-1 DEM C - Hillshaded model processed from SRTM 


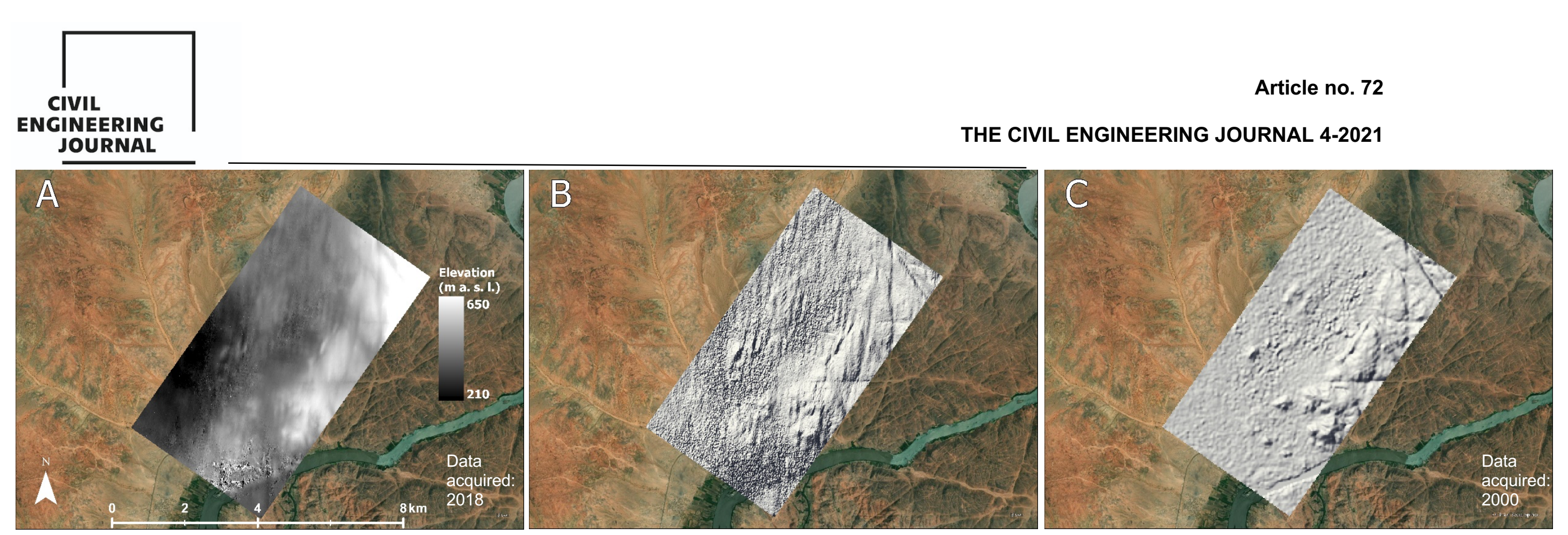

Fig. 6: Resulting models of the Sabaloka locality, author: Dominik Brétt, 2021, source: Esri, Maxar, Earthstar Geographics, USDA FSA, USGS, Aerogrid, IGN, IGP,

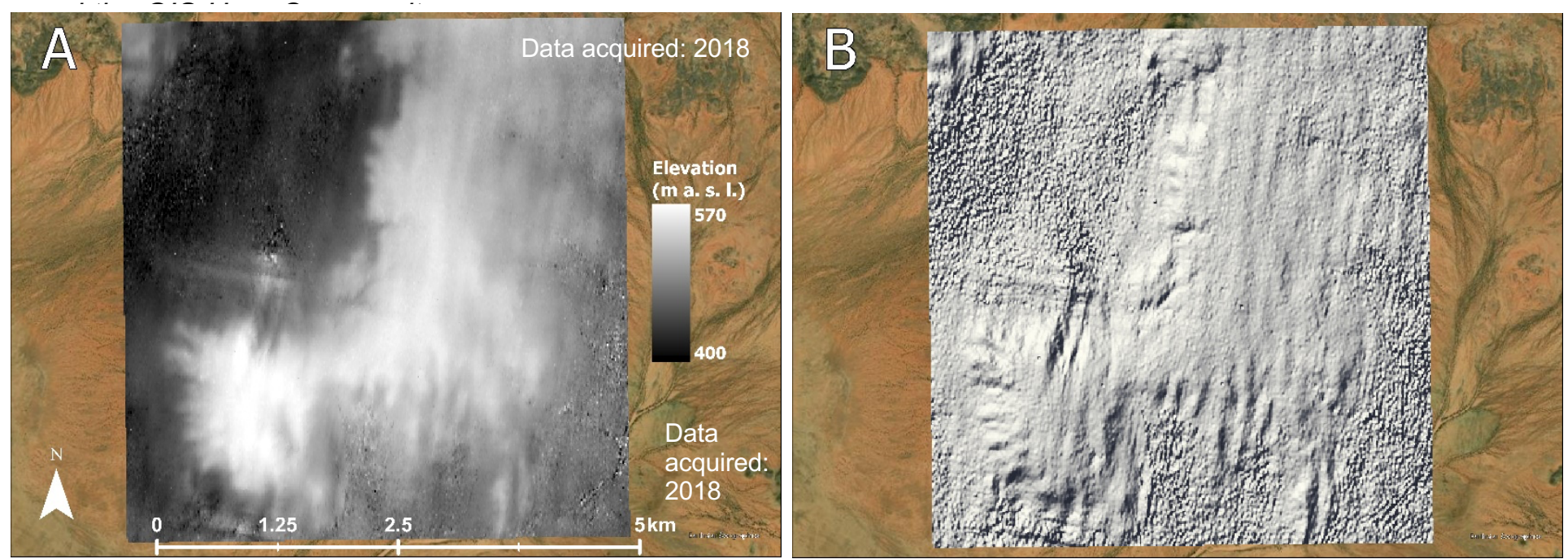

Fig. 7 - Resulting models of the Shaquadud localit, author: Dominik Brétt, 2021, source: Esri, Maxar, Earthstar Geographics, USDA FSA, USGS, Aerogrid, IGN, IGP, and the GIS User Community DOI 10.14311/CEJ.2021.04.0072

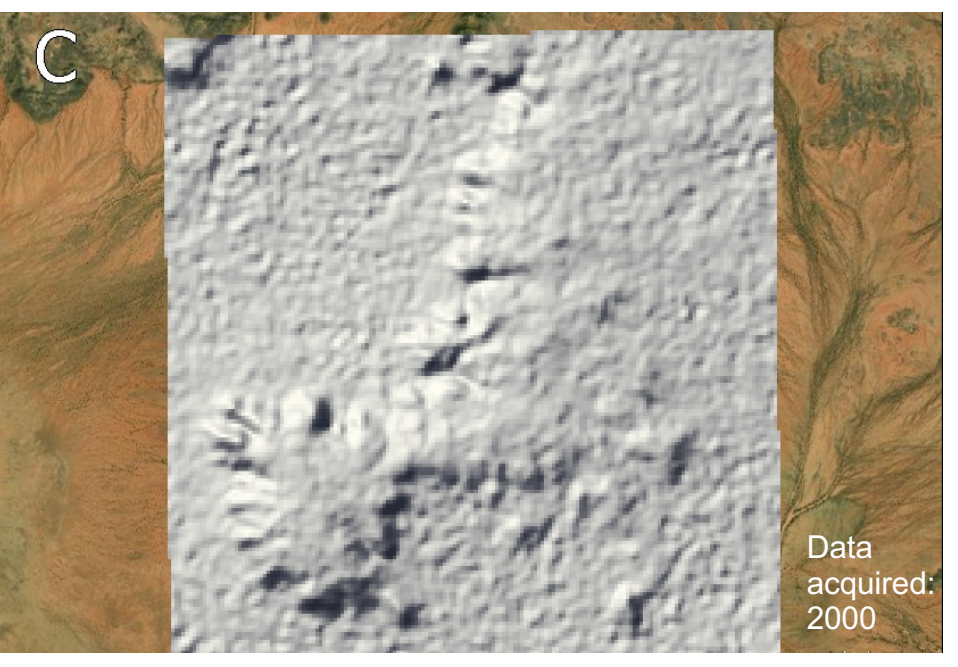

A - DEM processed from Sentinel-1 data

B - Hillshaded model processed from Sentinel-1 DEM C - Hillshaded model processed from SRTM 


\section{Accuracy of the produced DEMs}

The quality of the resulting DEMs was checked using different data sources. The residuals in the $Z$ coordinates were analyzed and the quality of the resulting models was verified also statically using RMSE. All four localities were compared with the SRTM data. Altogether in the first test comparison with the SRTM data, 25 points were set as the expected sufficient minimum sample size, and those points were randomly created and used for statistical analysis in each of the localities.

In Sudan, points were acquired by direct measurement. A total number of 45 points for the Sabaloka and 95 points for the Shaquadud locality were used. The sites in the Czech Republic were also compared to DMR 5G where another 100 points were tested. The results of the accuracy analysis are presented in Tab. 1.

Tab. 1: Results of the RMSE in meters

\begin{tabular}{|c|r|r|r|r|}
\hline & \multicolumn{2}{|c|}{ Czech Republic } & \multicolumn{2}{c|}{ Sudan } \\
\cline { 2 - 5 } & Žatec (m) & $\begin{array}{c}\text { Quarry Bílina } \\
(\mathbf{m})\end{array}$ & Sabaloka (m) & $\begin{array}{c}\text { Shaquadud } \\
(\mathbf{m})\end{array}$ \\
\hline $\begin{array}{c}\text { Sentinel-1 and } \\
\text { SRTM }\end{array}$ & 25.7 & 104.2 & 26.9 & 10.8 \\
\hline $\begin{array}{c}\text { Sentinel-1 and } \\
\text { GCP }\end{array}$ & 71.8 & - & 32.3 & 23.3 \\
\hline $\begin{array}{c}\text { Sentinel-1 and } \\
\text { Lidar }\end{array}$ & & 79.4 & & \\
\hline
\end{tabular}

As regards the quality of the INSAR altitude model, according to the ESA Forum, the normal deviation of RMSE when compared to SRTM ranges from -75 meters to 75 meters and models have to fit within this certain error size. SRTM digital height models had a pixel resolution of about 30 meters, while digital height models from data Sentinel-1 15 meters.

The areas chosen in Sudan turned out better both visually and statistically. The RMSE value of Sudan's first Sabaloka area was 26.935 meters in comparison with SRTM and 32.338 meters in comparison with directed measurements. In the second area Shaquadud was RMSE value 10.839 meters and in comparison with direct measurements 23.339 meters.

The height data from the SRTM are from 2000 and in the Bílina quarry area, it is clear that there has been a development and process of mining and therefore the data could have been misleading since it was a comparison of heights 18 years later. The RMSE deviation when comparing interferometric data with SRTM was 104.169 meters. The RMSE of the Žatec area turned out better with a value of 25.723 meters. Compared to lidar data Žatec area did not meet the expectations and the RMSE value raised to almost 72 meters. Another test was made and the RMSE was compared between data from Sentinel-1 and SRTM, where the same 100 points were tested and the result was 68.03078. The DEM of the area of the quarry Bílina made from the Sentinel-1 data was also compared to DMR 5G. The data from DMR was acquired in the year 2013 so the data were closer to terrain to the Sentinel-1, which were acquired, in this case, in the year 2018. RMSE value of the quarry Bílina dropped in the second test with the lidar data from almost 105 meters to 79 meters.

Even though in the Czech Republic, areas were chosen in the period of the dormancy, the author did not succeed to find paired interferometric images that had comparable RMSE values to the Sudan areas and excessive occurrence of noise has harmed the quality of the shaded models and models display the terrain very roughly. 


\section{CONCLUSION}

The results of digital elevation models processed from Sentinel- 1 interferometric data were verified against a commonly available elevation model derived from the data of the satellites SRTM. The application of these models is especially suitable for areas that are poorly available for other and more accurate methods of obtaining elevation data. Models processed from Sentinel-1 data turned out much better for areas in Sudan, even though the time difference between individual images was 12 days compared to 3 days for areas in the Czech Republic. 25 testing points were insufficient amount for areas in the vegetated areas - in the Czech Republic.

Processing of the Sentinel- 1 data is more complex and the user has to find suitable paired images - which take the most time during the processing itself when selecting a less suitable locality, especially with occurring vegetation. This is followed by pre-processing the images to create a digital model. In SRTM processing user has to choose suitable tiles with prepared DEM.

SRTM provides satellite data that is not as accurate as the direct measurement methods, and the RMSE value, when compared to Sentinel-1 data is therefore lower and appears to be of better quality. On the other hand, the data from GNSS instruments are very accurate and so the deviation when comparing the data is higher.

Satellite data can be useful for areas that are poorly accessible and more accurate methods cannot be used. Then the Sentinel data can provide 14-meter resolution and relatively accurate models for suitable areas (primarily arid areas).

The results of the digital elevation models processed from the Sentinel-1 interferometric data were verified with a commonly available elevation model acquired by the SRTM. The use of these models is especially suitable for areas that are poorly accessible to other alternative and more accurate methods of obtaining altitude data cannot be used. The Sentinel data can provide 14-meter resolution and relatively accurate models for suitable areas (primarily arid areas) that have a minimum of the surrounding vegetation which can also harm the quality of the models. It can be seen for the Sudan areas as the example of the arid areas and in comparison with the Czech areas.

\section{ACKNOWLEDGEMENTS}

This work was supported by Project Number: UJEP-SGS-2019-44-001-3 (Spatial data remote sensing methods as a tool for modeling and observing the environment) covered by student grant competition at UJEP - Jan Evangelista Purkyně University in Ústí nad Labem.

The reference data for test sites in Sabaloka, Sudan were supplied by the Czech Institute of Egyptology, Faculty of Philosophy and Arts - Charles University in Prague (L. Varadzinová) and the data for the site in Shaquadud, Sudan were supplied by the Institute of archaeology of the Czech academy of sciences, Prague (L. Varadzin).

\section{REFERENCES}

1. SONG, Dunjiang, Tianxiang YUE a Zhengping DU. DEM Construction from Contour Lines Based on Regional Optimum Control. In: 2010 Third International Joint Conference on Computational Science and Optimization [online]. IEEE, 2010, 2010, s. 162-165 [cit. 2021-11-30]. ISBN 978-1-4244-6812-6. Available from: doi:10.1109/CSO.2010.87

2. JARIHANI, Abdollah A., John N. CALLOW, Tim R. MCVICAR, Thomas G. VAN NIEL a Joshua R. LARSEN. Satellite-derived Digital Elevation Model (DEM) selection, preparation and correction for hydrodynamic modelling in large, low-gradient and data-sparse catchments. Journal 
of Hydrology [online]. 2015, 524, 489-506 [cit. 2021-11-30]. ISSN 00221694. Available from: doi:10.1016/j.jhydrol.2015.02.049

3. LAZNA, Tomas, et al. Cooperation between an Unmanned Aerial Vehicle and an Unmanned Ground Vehicle in Highly Accurate Localization of Gamma Radiation Hotspots. International Journal of Advanced Robotic Systems, Jan. 2018, doi:10.1177/1729881417750787.

4. MASSONNET, Didier. Satellite Radar Interferometry. Scientific American, vol. 276, no. 2, Scientific American, a division of Nature America, Inc., 1997, pp. 46-53, http://www.jstor.org/stable/24993607.

5. Collaborative Ground Segment - Czech Republic, Sentinel-1 - Datové specifikace [online]. [cit. 2020-03-08]. Available from: https://collgs.czechspaceportal.cz/sentinel-1-datove-specifikace/ 6. FLETCHER, K. Sentinel-1: ESA's Radar Observatory Mission for GMES Operational Service. Noordwijk, Netherlands: ESA Communications, 2012. ISBN 978-92-9221-418-0.

7. LISÁ, Lenka, BAJER Aleš, PACINA Jan, McCOOL Jon-Paul, CíLEK Václav, ROHOVEC Jan, MATOUŠKOVÁ Šárka, KALLISTOVA Anna a Zdeněk GOTTVALD. Prehistoric Dark Soils/Sediments of Central Sudan; Case Study From the Mesolithic Landscape at the Sixth Nile Cataract. CATENA. ISSN: 0341-8162

8. PACINA, Jan. Geodetic surveying as part of archaeological research in Sudan. Geoinformatics FCE CTU. 2015, 14(1): 47-63.

9. VARADZINOVÁ SUKOVÁ, Lenka, Ladislav VARADZIN, Aleš BAJER, Lenka LISÁ, Jan PACINA a Petr POKORNÝ. Tracing Post-depositional Processes at Mesolithic Occupation Sites in Central Sudan: View from the Site of Sphinx (SBK.W-60) at Jebel Sabaloka. Interdisciplinaria Archaeologica - Natural Sciences in Archaeology (IANSA). 2015, 6(2), 133-150. ISSN 1804-848X. 10. NATURAL RESOURCES CANADA. Fundamentals of Remote Sensing [online]. [cit. 202104-20]. Available from:

https://www.nrcan.gc.ca/sites/www.nrcan.gc.ca/files/earthsciences/pdf/resource/tutor/fundam/pdf/f undamentals_e.pdf

11. DOBROVOLNÝ, Petr. Remote Sensing: Digital Image Processing (Dálkový průzkum Země: Digitální zpracování obrazu). Brno, 1998. ISBN 80-210-1812-7.

12. Remote Sensing: Digital Image Processing (Copernicus v České republice. Družice Sentinel) [online]. [cit. 2021-06-06]. Available from: http://copernicus.gov.cz/druzice-sentinel 13. BOURGEAU-CHAVEZ, Laura, Kevin RIORDAN, Richard POWELL, Nicolle MILLER a Mitch NOWELS. Improving wetland characterization with multisensor, multi- Improving wetland characterization with multi-sensor, multitemporal SAR and optical/infrared data fusion [online]. 2009 [cit. 2021-05- 05]. Available from: http://www.dx.doi.org/10.5772/46139 
14. BRAUN, Andreas a Luis VECI. TOPS Interferometry Tutorial [online]. 2015 [cit. 2021-0606]. Available from: http://step.esa.int/docs/tutorials/S1TBX\%20TOPSAR\%20Interferometry\%20wit h\%20Sentinel-1\%20Tutorial_v2.pdf

15. ROTT, Helmut. Advances in interferometric synthetic aperture radar (InSAR) in earth system science, Institute of meteorology and geophysics. Institute of meteorology and geophysics: University of Innsbruck, 2009.

16. GUPTA, Ravi P. Remote Sensing Geology. 2. New York: Springer, 2003. ISBN 978-3-64207741-8.

17. ESA SENTINEL ONLINE. Sentinel Overview [online]. [cit. 2021-04-08]. Available from: https://sentinel.esa.int/web/sentinel/missions/

18. Alaska Satellite Facility - [online]. [cit. 2021-06-06]. Available from: https://search.asf.alaska.edu/\#/

19. Copernicus Open Access Hub [online]. [cit. 2020-03-08]. Available from: https://scihub.copernicus.eu/dhus/\#/home

20. Collaborative Ground Segment - Czech Republic [online]. [cit. 2021-06-06]. Available from: https://dhr1.cesnet.cz/\#/home

21. U.S. GEOLOGICALSURVEY. USGS EROS Archive - Digital Elevation - Shuttle Radar Topography Mission (SRTM) 1 Arc-Second Global [online]. [cit. 2021-06-15]. Available from: https://www.usgs.gov/centers/eros/science/usgs-eros-archive-digital-elevation-shuttle-radartopography-mission-srtm-1-arc?qt-science_center_objects=0\#qt-science_center_objects 22. SRTM image courtesy of the U.S. Geological Survey. Available from: https://earthexplorer.usgs.gov/

23. Czech Office for Surveying and Cadastre: Digital model of the relief of the Czech Republic 5th generation (DMR 5G)(Český úřad zeměměřičský a katastrální: Digitální model reliéfu České republiky 5. generace (DMR 5G)) [online]. [cit. 2021-10-15]. Available from: https://geoportal.cuzk.cz/(S(z5hdhew0ycnv515y22ujq0a1))/Default.aspx?mode=TextMeta\&side=vy skopis\&metadataID=CZ-CUZK-DMR5G-V\&head_tab=sekce-02-gp\&menu=302 